\title{
Kajian dampak transformasi desain Nokia 3310 terhadap minat pasar Nokia di Indonesia
}

\author{
Kevin Ahmed Akbar* \\ Fakultas Seni Rupa dan Desain, Institut Teknologi Bandung, Indonesia
}

\begin{abstract}
Nokia mobile phone is one of the famous mobile phone brands carrying the slogan 'Connecting People' with the intention of presenting a mobile phone that can be used by everyone. Nokia is targeting a large market share, where every mobile phone made can be obtained by many people and with a design that is not inferior to other brands. One of the famous mobile phones ever produced by Nokia is the Nokia 3310 series which in its time Nokia 3310 phone is very in demanded because of its good design and resiliency. Then in 2017 comes the new Nokia 3310 series featuring a more modern design with a more developed specification than the previous Nokia 3310 series with the intention to hook the Nokia consumers who miss the Nokia 3310 but still feel the phone is not outdated. This research is a qualitative research based on the application of product design principles at Nokia 3310 - 2017.
\end{abstract}

Keywords: tranformation, design, celuller phone, interest, market, spesification

\begin{abstract}
Abstrak
Ponsel Nokia merupakan salah satu merek ponsel terkenal yang mengusung slogan 'Connecting People' yang memiliki maksud bahwa Nokia menyajikan ponsel yang dapat digunakan oleh semua orang. Nokia mengincar pangsa pasar yang cukup luas, dimana setiap ponsel yang dibuat dapat diperoleh oleh banyak kalangan dan dengan desain yang tidak kalah dengan merek lain. Salah satu ponsel yang terkenal yang pernah diproduksi oleh Nokia adalah seri Nokia 3310 yang pada masanya ponsel Nokia 3310 ini sangat diminati karena desainnya yang bagus dan tahan banting. Kemudian pada tahun 2017 muncul seri Nokia 3310 yang baru dengan menampilkan desain yang lebih modern dengan spesifikasi yang lebih berkembang dari seri Nokia 3310 sebelumnya dengan maksud menggaet konsumen Nokia yang rindu akan Nokia 3310 namun tetap merasa ponselnya tidak ketinggalan zaman. Penelitian ini merupakan penelitian kualitatif berdasarkan penerapan prinsip desain produk pada Nokia $3310-2017$.
\end{abstract}

Kata kunci: transformasi, desain, ponsel, minat, pasar, spesifikasi.

\section{Pendahuluan}

Perkembangan teknologi menuntut orang untuk lebih berkembang maju. Sarana komunikasi menjadi sangat penting pada masa kini, dimana komunikasi sudah menjadi kebutuhan yang utama bagi masyarakat modern. Hal ini membuat persaingan para pelaku dunia usaha di bidang industri ponsel untuk saling memproduksi ponsel yang lebih menarik di mata konsumen dari produsen ponsel lainya. Para pelaku usaha ini pun melakukan banyak pengembangan untuk menghasilkan inovasi untuk ponsel yang akan mereka produksi. Inovasi ponsel pun berkembang di sekitar pengembangan desain ponsel yang menarik, persaingan dalam memunculkan ponsel dengan spesifikasi yang lebih dari ponsel lainnya, dan bahkan ada beberapa produsen ponsel ingin menguasai tingkat pasar tertentu.

Fitur ponsel pada masa ini makin banyak berkembang, ponsel bukan hanya menjadi sebuah alat komunikasi semata, namun memiliki tambahan fitur yang semakin membuat manusia sangat bergantung kepada ponsel. Ponsel zaman sekarang memiliki aplikasi pemutar musik, browser, aplikasi media gambar, sosial media, dan lain sebagainya. Fitur-fitur tersebut menjadi pendongkrak minat konsumen konsumen terhadap produk ponsel. Nilai "estetika" sebuah ponsel pun menjadi sebuah roket pendorong

\footnotetext{
* Koresponden penulis e-mail : kevienahmeda@gmail.com
} 
minat konsumen, menaikan nilai suatu barang menjadi tugas dari "estetika" dalam desain sebuah produk. Tampilan yang menarik menjadi nilai tambah dan juga bisa menjadi kebanggan tersendiri bagi si pemilik ponsel.

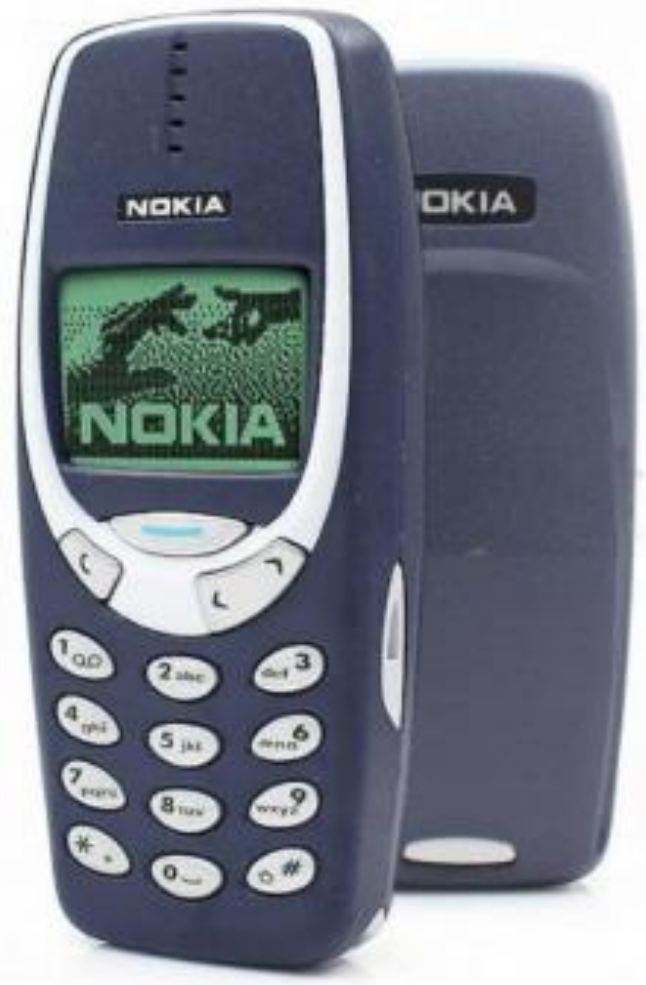

Gambar 1. Desain ponsel Nokia 3310 lama (Sumber: https://www.extremetech.com/wpcontent/uploads/2017/02/Nokia-3310-640x353.png )

Di pasaran Nokia merupakan salah satu merek yang sangat terkenal oleh masyarakat Indonesia. Nokia pertama kali diciptakan di Finlandia, dan mulai beroperasi pada awal tahun 1980. Sejak berdiri, Nokia telah berhasil 3 memimpin di pasaran, dan bisnis Nokia telah berkembang di semua negara untuk memenuhi kebutuhan pelanggan dan perkembangan industri telekomunikasi di berbagai negara termasuk Indonesia. Posisi Nokia kini terancam eksistensinya oleh vendorvendor yang sedang berkembang pesat yakni Apple dan RIM (Research In Motion), yang memiliki sistem operasi yang lebih baru dan lebih mutakhir mulai menggeser Nokia yang sudah tua.

Salah satu cara agar Nokia tidak tergeser oleh vendor lain adalah dengan memberikan sesuatu yang baru dan menarik dari sebelumnya. Oleh karena itu, pada tahun 2017 diluncurkanlah seri Nokia 3310 versi tahun 2017. Dengan mengambil ide untuk memperbaharui desain dari Nokia 3310 yang lawas dan menambahkan fitur yang lebih canggih dari pendahulunya. Nokia pun menggunakan cara agar konsumen mendapatkan perasaan nostalgia dengan ponsel Nokia versi pendahulu untuk meningkatkan penjualan.

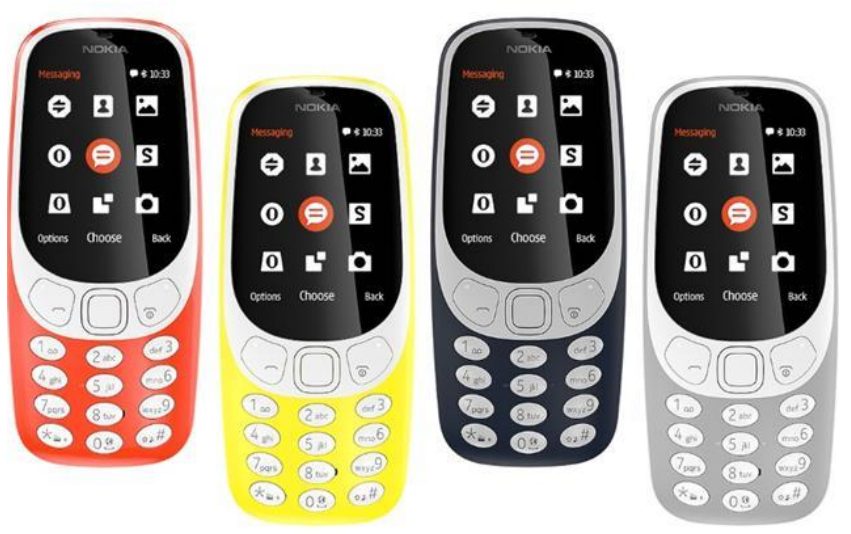

Gambar 2. Desain ponsel Nokia 3310 baru (Sumber:

http://drop.ndtv.com/TECH/product_database/images/2262017102715PM _635_nokia_3310.jpeg )

\section{Bahan dan Metode}

Penelitian mengenai dampak kajian transformasi desain Nokia 3310 terhadap minat di pasar Indonesia ini bertujuan untuk mencari tahu kerja sebuah desain terhadap pengembangan dari desain yang lama. Berdasarkan kasus ini, dengan mencari tahu perbandingan konsumen lama dan baru melalui kajian estetik dari respon langsung konsumen terhadap produk. Baik bentuk, warna, maupun segala aspek yang berkaitan dengan desain yang memengaruhi pemasaran. Penelaahan kasus tersebut berdasarkan pada penelitian kualitatif deskriptif dengan pendekatan studi terhadap lingkup kajian estetik yang bermaksud menginvestigasi faktor-faktor yang berpengaruh dari desain di pasaran.

Desain sebuah produk amatlah penting. Setiap desain akan menjadi daya tarik dan memberikan manfaat bagi para konsumen. Desain yang baik mampu memenangkan perhatian pasar sehingga memberikan keunggulan dan keuntungan bagi produsen.

Perkembangan mode dan tren mendorong para produsen ponsel untuk terus mengembangkan desain untuk memenuhi kebutuhan konsumen yang makin lama makin banyak jumlahnya. Ketika desain yang dibuat memenuhi harapan konsumen maka itu akan mempengaruhi kepuasan, kenyamanan atau prestise 
konsumen. Hal tersebut akan saling terkait dan menjadi unsur yang menarik konsumen untuk mengambil keputusan membeli. Dua aspek penting desain produk terkait dengan mode dan tren adalah warna dan branding. Setiap warna memiliki karakteristik tersendiri. Sifat dari warna antara lain hue (jenis warna), value (tingkat kecerahan dan kegelapan warna), dan chroma ( kualitas yang menyatakan kekuatan dan kelemahan warna). Dari sifat warna tersebuta dapat ditentukan adanya warna sejuk dan hangat.

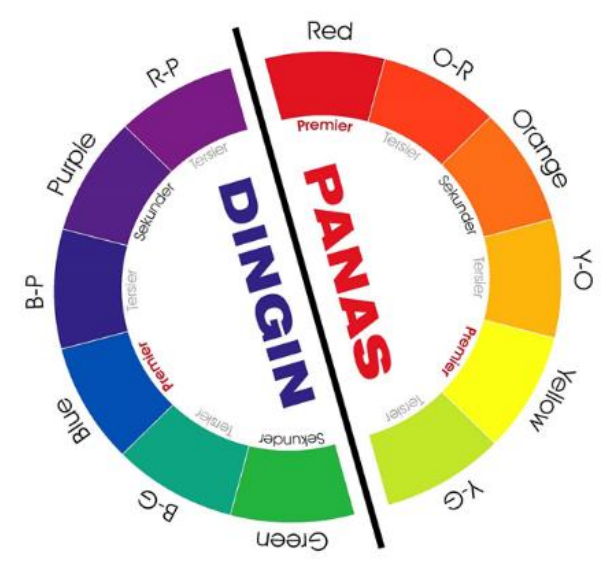

Gambar 3 . Skema Warna Panas dan Dingin (Sumber : http://1.bp.blogspot.com)

Dalam desain produk salah satu unsur yang mempengaruhi minat konsumen adalah warna yang ada pada produk tersebut. Warna berfungsi sebagai informasi berkaitan konten yang akan diberikan produsen kepada konsumen. Semakin banyak variasi yang diberikan, potensi ketertarikan konsumen pun akan semakin besar.

Sedangkan istilah branding dalam dunia bisnis mengacu pada kegiatan komunikasi yang dilakukan perusahaan dalam rangka proses membangun dan membesarkan merek mereka. Saat ini, pesatnya pertumbuhan dunia digital menyebabkan bergesernya juga tren dalam berkomunikasi. Penggunaan bahasa visual dalam penyampainan menjaga gaya baru. Orang berbondong-bondong untuk meningkatkan dunia kreatif. Hal ini menjadi angin segar bagi para penggiat dunia kreatif.

\section{Hasil dan pembahasan}

Setelah menganalisis faktor-faktor berkaitan tentang teori desain dan pemasaran yang memungkinkan berkaitan tentang dampak transformasi desain Nokia 3310 terhadap pasar Nokia di Indonesia, didapatkan bahwa dengan desain yang menarik. Menurut riset dari
Captify yang menganalisis pencarian secara online, peningkatan pencarian pada kata Nokia melesat sekitar 79,7\% sejak peluncuran Nokia 3310 versi baru pada tahun 2017. Desain bekerja pada saat konsumen melihat, dan ketertarikan sangat dimungkinkan akibat desain yang sesuai harapan dari pasar.

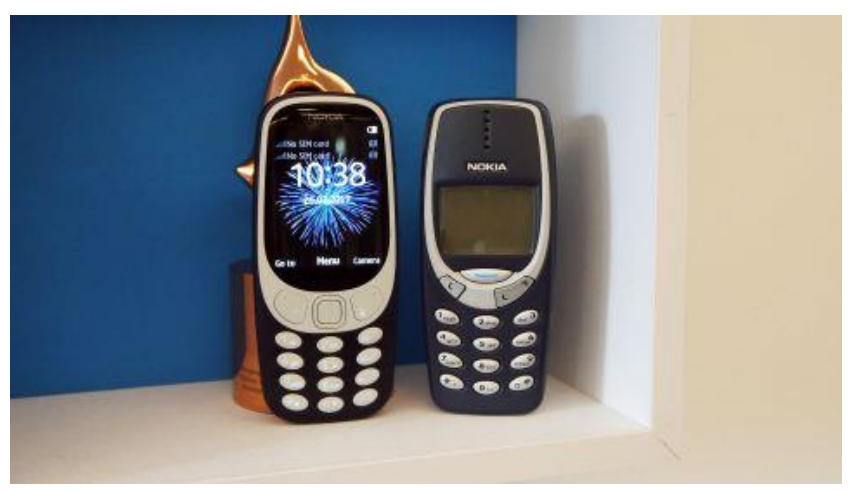

Gambar 4. Perbandingan Nokia 3310 klasik (kanan) dengan Nokia 3310 baru (kiri)

Sumber : http://cdn.mos.cms.futurecdn.net)

Desain Nokia 3310 terbaru memiliki bentuk yang lebih organis dan tidak terlalu kaku seperti Nokia klasik 3310, dan itu memenuhi kebutuhan konsumen masa kini yang serba praktis dan terlihat dinamis. Garis yang dipakai pada Nokia 3310 baru sangat modern, namun tanpa meninggalkan kesan Nokia 3310 klasik. Warna yang di berikan pada Nokia 3310 terbaru memiliki banyak variasi yang memungkinkan konsumen untuk bisa memilih warna apa yang mereka inginkan. Desain secara keseluruhanpun tampak lebih segar.

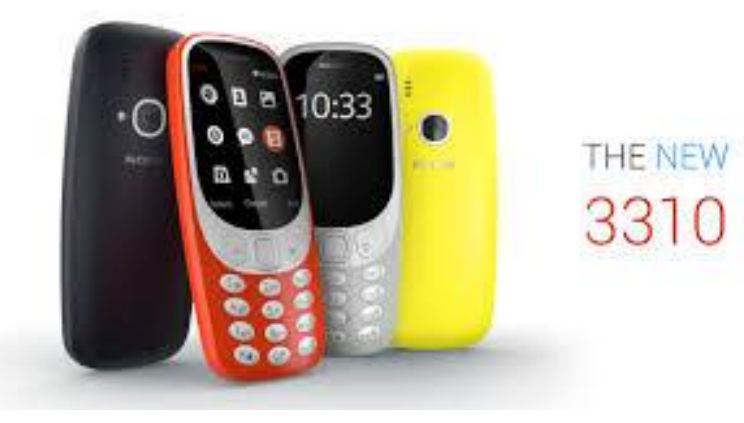

Gambar 5. Variasi Nokia 3310 baru (Sumber : https://3.bp.blogspot.com)

\section{Kesimpulan}


Dengan melakukan rebranding terhadap ponsel Nokia 3310, perusahaan Nokia berhasil menarik kembali perhatian konsumennya. Hal tersebut dapat dilihat dari antusiasme para konsumen berkaitan dengan peluncuran desain terbaru Nokia 3310 yang telah memiliki tempat tersendiri di kalangan pengguna ponsel genggam Nokia. Berkaitan dengan hal tersebut dapat disimpulkan bahwa perancangan ulang (redesign) suatu produk dengan melihat faktor-faktor yang berpengaruh, seperti perkembangan zaman, tren, dan kebutuhan masyarakat akan dapat mengembalikan perhatian konsumen terhadap produk tersebut.

\section{Daftar pustaka}

Alaman, A.Y., Hidayat, W., \& Djoko W.H. (2013) Pengaruh citra merek, desain, dan fitur produk terhadap keputusan pembelian handphone Nokia (Studi kasus pada Mahasiswa Universitas Diponegoro). Semarang: Jurusan Manajemen, Fakultas Ekonomi, Universitas Diponegoro

Cenadi, S.A. (2000) Peranan desain kemasan dalam dunia pemasaran. Jakarta: Jurusan Desain Komunikasi Visual, Fakultas Seni dan Desain, Universitas Kristen Petra

Kristo, F. Y. (2017) Penjual Nokia 3310 Reborn heran minat pembeli sangat tinggi. https://inet.detik.com/consumer/d3440934/penjual-nokia-3310-reborn-heran-minat-pembelisangat-tinggi diakses pada 28 April 2017 09:00 